\title{
Pathogenesis and Management of Brain Tumor-Related Epilepsy
}

\author{
Srijan Adhikari • Blake C. Walker • Sandeep Mittal \\ Fralin Biomedical Research Institute, Virginia Tech Carilion School of Medicine, Roanoke, \\ VA, USA; Carilion Clinic - Neurosurgery, Roanoke, VA, USA
}

Author for correspondence: Sandeep Mittal, Virginia Tech Carilion School of Medicine, 2331 Franklin Rd SW, Suite 2154, Roanoke, VA, USA. Email: sandeepmittal@vt.edu

Doi: https://doi.org/10.36255/exonpublications.gliomas.2021.chapter12

\begin{abstract}
Up to $50 \%$ of patients with brain tumors will initially present with seizures, while an additional 10-30\% will develop seizures during the course of the disease. Gliomas are the most common primary intracranial tumors and are associated with a number of changes which are involved in the pathogenesis of epilepsy, including blood-brain barrier disruption, molecular changes, edema, and peritumoral environmental changes. Epilepsy is a source of significant morbidity and mortality for patients with gliomas. The two main treatments for patients with glioma-related epilepsy involve antiepileptic drugs as well as surgical resection of the mass and surrounding epileptogenic tissue, if feasible. Given the propensity for neighboring tissue to also be epileptogenic, intraoperative electrocorticography can be of benefit to define the seizure onset and spread areas. Surgical treatment of glioma-associated epilepsy can provide significant relief for affected patients. Unlike non-lesional epilepsy, which is primarily managed medically, glioma-related epilepsy frequently requires surgery because of its medically refractory nature.
\end{abstract}

Keywords: anti-epileptic drugs; high-grade gliomas; intractable epilepsy; refractory seizures; tumor-associated epilepsy

In: Gliomas. Debinski W (Editor). Exon Publications, Brisbane, Australia. ISBN: 978-0-6450017-4-7; Doi: https://doi.org/10.36255/exonpublications.gliomas.2021

Copyright: The Authors.

License: This open access article is licenced under Creative Commons Attribution-NonCommercial 4.0 International (CC BY-NC 4.0) https://creativecommons.org/licenses/by-nc/4.0/ 


\section{INTRODUCTION}

Seizures are one of the common presenting symptoms of brain tumors, accounting for up to 50\% of initial presentations. One third of patients diagnosed with a brain tumor will develop seizures during the clinical course if they did not initially present with seizures (1-4). Although the incidence of seizures is high among brain tumor patients, the incidence of intracranial tumors as an underlying etiology of epilepsy is relatively low $(3,5)$. Despite significant advances, management of seizures in patients harboring a brain tumor remains challenging. These difficulties arise from suboptimal response to anticonvulsants, interplay between antiepileptic drugs (AEDs) and chemotherapeutic agents, and possible adverse effects of both medical and surgical treatment. Seizures can tremendously affect patients' quality of life and negatively impacts overall survival (6). The focus of this chapter will be new literature and guidelines related to brain tumor-related epilepsy (BTRE).

\section{EPIDEMIOLOGY AND PATHOGENESIS}

The exact pathophysiology of BTRE is not well characterized; however, it is thought to be multifactorial (Figure 1) $(7,8)$. Tumor burden, type, location, growth rate, microenvironment of the blood-brain barrier, altered neurotransmitter homeostasis, and gap junction alterations are factors that influence

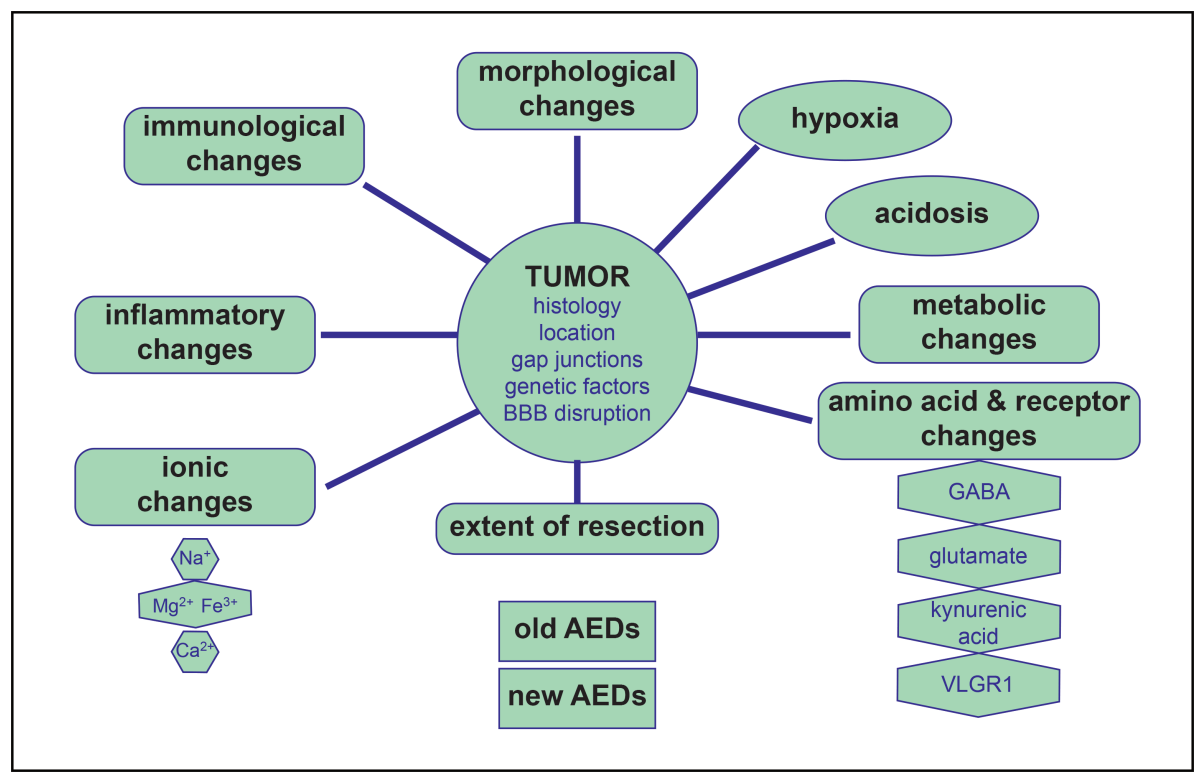

Figure 1. Known mechanisms underlying the pathogenesis of brain tumor-related epilepsy. Modified from Wu et al. (39). 
$\operatorname{BTRE}(7,8)$. The likelihood of epilepsy among patients with brain tumors differs depending on the tumor's histopathological subtype. Patients with lowgrade gliomas have a greater tendency to suffer from seizures than those with high-grade gliomas. One study found that patients diagnosed with low-grade glioma had a significantly higher rate of seizures compared to patients diagnosed with glioblastoma ( $85 \%$ vs. $49 \%$, respectively) (9). Dysembryoplastic neuroepithelial tumors (DNETs) and gangliogliomas have an extremely high propensity for seizures with an incidence greater than $80 \%(3,10)$. Metastatic lesions tend to have a low incidence of seizures $(9,11,12)$. Melanoma, however, has the highest seizure rate among the metastatic lesions because it involves gray matter, frequently has multiple lesions, and has an intrinsic high frequency of hemorrhage $(13,14)$.

\section{Tumor Location}

Tumor location is one of the most important aspects to consider when it comes to tumor epileptogenesis. Cortical tumors involving the frontal, temporal and parietal cortices as well as tumors in the cortical gray matter are associated with greater seizure frequency compared to lesions involving the infratentorial region, suprasellar region, or occipital lobe (Table 1$)(1,10)$. Seizure type is also associated with anatomical location of tumor. For example, focal awake seizures are associated with lesions involving left inferior and middle frontal gyrus, while focal unaware seizures are associated with the right temporal-insular region (15).

\section{Tumor Growth Rate}

Studies show that seizure prevalence and tumor growth rate are inversely proportional (9). Intuitively, slower growing and more indolent gliomas have a longer amount of time to provoke a seizure. Moreover, epileptogenesis requires complex re-organization and vascularization of tumor cells which often does not happen with rapidly growing tumors (7). Moreover, slow growing neoplasms tend to possess innate epileptogenic properties (7).

The pathogenesis of epilepsy differs among the various types of tumors. Tumors such as DNETs have high incidence of seizure because they tend to cause

\section{TABLE 1 Seizures by tumor location in 65 patients with gliomas. Adapted from Lote et al. 1995 (9)}

\begin{tabular}{lcccc} 
Tumor Location & $\begin{array}{c}\text { Seizure at } \\
\text { Onset }\end{array}$ & $\begin{array}{c}\text { Recurrent } \\
\text { Seizures }\end{array}$ & $\begin{array}{c}\text { Late Onset } \\
\text { Seizures }\end{array}$ & $\begin{array}{c}\text { Status } \\
\text { Epilepticus }\end{array}$ \\
\hline Frontal & $10 / 19$ & $8 / 10$ & $2 / 9$ & $0 / 19$ \\
Temporal & $3 / 11$ & $3 / 3$ & $2 / 8$ & $1 / 11$ \\
Parietal & $10 / 24$ & $7 / 10$ & $3 / 14$ & $5 / 24$ \\
Occipital & $0 / 2$ & - & $2 / 2$ & $1 / 2$ \\
Multifocal/Bilateral & $6 / 9$ & $3 / 6$ & $1 / 3$ & $3 / 9$
\end{tabular}


cortical disruption due to disruption of the underlying cortical and subcortical structures $(3,10)$. The mechanisms behind the higher seizure frequency of other low-grade lesions is likely secondary to mechanical and vascular changes which slowly develop overtime (10). In contrast, high-grade gliomas and other rapidly dividing tumors tend to cause seizures because of irritation from necrosis or products of hemorrhage, such as hemosiderin (10, 16-21).

\section{Neurotransmitters and Gap Junctions}

Various animal and human tissue studies have identified glutamate, $\gamma$-aminobutyric acid (GABA), and adenosine kinase (ADK) as possible contributory factors for epileptogenesis in patients with brain tumors (22-24). Glioma studies in animals illustrated that seizure activity originated due to elevated glutamate production causing hyperexcitability around the peritumoral area (22). Studies comparing patients with lesion-associated medically refractory epilepsy and patients with similar lesions but no clinical epilepsy demonstrated that approximately $73 \%$ of tissue obtained from patients with lesional refractory epilepsy shows disruption of GABA and N-methyl-D-aspartate (NMDA) receptors (19). Dysregulation of ADK among the peritumoral tissue has also been hypothesized to induce seizure activity among patients with brain tumors. One study comparing normal brain tissue with excised epileptogenic foci of patients with epilepsy showed higher expression ADK in tissue of epilepsy patients (23). Disruption of the blood-brain barrier can also cause dysregulation of neurotransmitters such as glutamate and GABA and can contribute to BTRE (25). A recent study noted that proteolytic enzymes released by tumor cells disrupt perineuronal nets resulting in decreased GABAergic inhibition and overall excitation/inhibition imbalance (26).

One of the main functions of gap junctions in the brain is intercellular communication. Connexin 43 (CX43) is an important transmembrane protein and functional element of gap junction; its expression was found to be high in glial cells, such as astrocytes (27). Peritumoral cells in low-grade gliomas also express CX43 to a greater extent than the peritumoral cells of high-grade gliomas, which could be a reason why patients with low-grade gliomas have seizures more frequently than patients with malignant gliomas (28-31). Unsurprisingly, drugs that target gap junctions may have an anticonvulsant effect $(30,31)$.

\section{Molecular Genetics and Peritumoral Environmental Changes}

The genetic implications of BTRE are poorly understood. Genes such as LGI1 (a tumor-suppressor gene) and phosphatase and tensin homolog (PTEN) have been associated with gliomas and epilepsy; however, their exact role in epileptogenesis is not well characterized (32-35). The microenvironment and neurotransmission between peritumoral tissue and normal brain tissue is vastly different (36). Gliomas cause disruption of the blood-brain barrier in surrounding tissue by changing the endothelial permeability which can lead to vasogenic edema, inflammatory changes, poor perfusion, and changes in hemostasis (37). All these microenvironmental changes in peritumoral tissue can lead to sodium and calcium imbalance in the neuronal cells eventually causing hyperexcitability and seizures $(19,20,38,39)$. 


\section{CLINICAL PRESENTATION}

It is well documented that BTRE causes significant burden in quality of life, mental status, cognition, and morbidity (40-43). The clinical manifestation of seizures related to brain tumors are usually focal or generalized with motor onset. Focal seizures are mostly location-dependent and correspond to specific function. For example, involvement of the precentral gyrus will typically manifest as focal motor seizures involving the contralateral extremities. Visual changes, altered mental status, behavioral changes, or altered sensorium could also be clinical symptoms associated with tumor-related seizures. Patients can also experience postictal Todd's paralysis, severe agitation with psychosis, and status epilepticus (SE) (44). The rate of SE in patients with brain tumors is variable; however, approximately $7 \%$ of all SE cases can be attributed to brain tumors (45). Patients who suffer from SE and brain tumors have higher 30-day mortality when compared patients with SE who do not have brain tumors (46). As mentioned above, patients with lowgrade gliomas are more likely to have seizures compared to patients with highgrade gliomas (9). Additionally, patients with low-grade gliomas are more likely to have secondary generalized seizures. Focal aware seizures are more common among patients with high-grade gliomas (47).

\section{MEDICAL MANAGEMENT OF BTRE}

Epilepsy can be defined as at least two unprovoked seizures occurring more than 24 hours apart or one unprovoked seizure with at least $60 \%$ probability of another one occurring over the next 10 years. With this definition, any patient with a brain tumor who has one seizure will automatically have epilepsy (48). As a result, it is imperative to treat these patients with AEDs to prevent seizures and their complications.

The American Association of Neurology (AAN), the Congress of Neurological Surgeons (CNS), and the American Society of Therapeutic Radiology and Oncology (ASTRO) all recommend withholding AEDs in brain tumor patients who have not had a seizure. In an instance where an AED has been started, it is recommended to withdraw after the first week of surgery (4). BTRE patients, however, need AEDs to prevent further seizures. AEDs such as levetiracetam, lamotrigine, lacosamide, topiramate, and pregabalin are recommended as they have favorable side effect profiles $(49,50)$. In a retrospective study comparing seizure control rates and adverse effects of levetiracetam and valproic acid (VPA), both AEDs show similar seizure control rates. VPA had a statistically significant higher rate of adverse drug effect when compared to levetiracetam (51). Another study demonstrated that patients with BTRE and high-grade gliomas tended to require multiple AEDs for seizure prophylaxis (47). VPA or a combination of VPA and levetiracetam had more success in controlling seizures than other agents (47).

Drug-drug interactions present some additional challenges in patients with BTRE who are taking multiple medications, including one or more AEDs with or without chemotherapy. AEDs that are metabolized in the liver have the most interactions with other drugs. Phenobarbital, carbamazepine, oxcarbazepine, and phenytoin are classically known for their enzyme inducing abilities, allowing faster 
metabolism of chemotherapy drugs such as methotrexate, steroids, paclitaxel and so on, potentially compromising the efficacy of oncological treatment (52).

Monotherapy is preferred when it comes to BTRE as it safer for the patient and compliance is less of an issue. Nonetheless, patients having seizures refractory to AED monotherapy will require additional agents. This is more common among patients with BTRE. In a study of 99 patients with BTRE, more than half did not respond to one AED. Among the non-responders, VPA and levetiracetam was the most effect combination to prevent further seizures (47). Studies have demonstrated that more than $50 \%$ of patients continue to have seizures despite the maximal medical management $(1,53)$. Seizures refractory to two AEDs will likely not be controlled with additional medications (54).

\section{Surgical Treatment}

Surgery is essential for diagnosis and treatment of brain tumors. In patients with BTRE, surgery is required for tissue diagnosis, reduction of tumor burden and mass effect, as well as seizure management. One study demonstrated that twothirds of the epileptogenic focus of patients with BTRE is located within or adjacent to the tumor (55). Thus, surgical intervention can often be curative for patients with BTRE (56). In patients with BTRE who failed medical management with two first line AEDs, surgery can be beneficial for seizure control $(4,54,57)$. In one series of 207 patients, $82 \%$ of patients with BTRE were seizure-free following tumor resection (56). This study also demonstrated that patients with one seizure focus tended to have better outcomes than patients with multiple seizure foci (56). A meta-analysis involving 773 patients with BTRE who underwent surgical resection showed approximately $71 \%$ were seizure-free after surgery $(57,58)$. The authors also demonstrated that patients who underwent gross total resection of the tumor had higher seizure freedom rates (58). As previously described, DNETs and ganglioglioma have higher frequency of seizures at presentation and they can be especially resistant to anticonvulsants. Thus, these patients often require surgical treatment $(40,55)$.

Surgical planning for medically refractory epilepsy starts with obtaining a regular scalp EEG to localize the seizure focus; however, these non-invasive studies are generally not adequate for precise seizure localization. Intracranial EEG with subdural grids, strip electrodes, and depth electrodes can be extremely helpful to accurately localize seizure focus and provide better outcome for patients with $\operatorname{BTRE}(59,60)$. Electrocorticography (ECoG) and stereoencephalography (SEEG) are techniques utilized to further help localize the seizure focus when scalp EEG is inconclusive or unclear.

Different surgical treatment options as well as advanced imaging modalities are available for patients with BTRE. Intraoperative cortical brain mapping with electrocorticography, radiosurgery, and laser interstitial thermal therapy are additional surgical techniques that can be effectively utilized in BTRE. EEG mapping is also another modality that can be beneficial for identifying the epileptogenic focus. Epileptogenic foci can be identified within or overlying the tumor, the peritumoral tissue, and even distant areas away from the tumor (Figure 2) (61, 62). The extent of tumor resected directly correlates with seizure freedom; however, patients may benefit from subtotal resection if the epileptic focus was identified before the resection, especially if the tumor is in eloquent areas of the brain (62). 


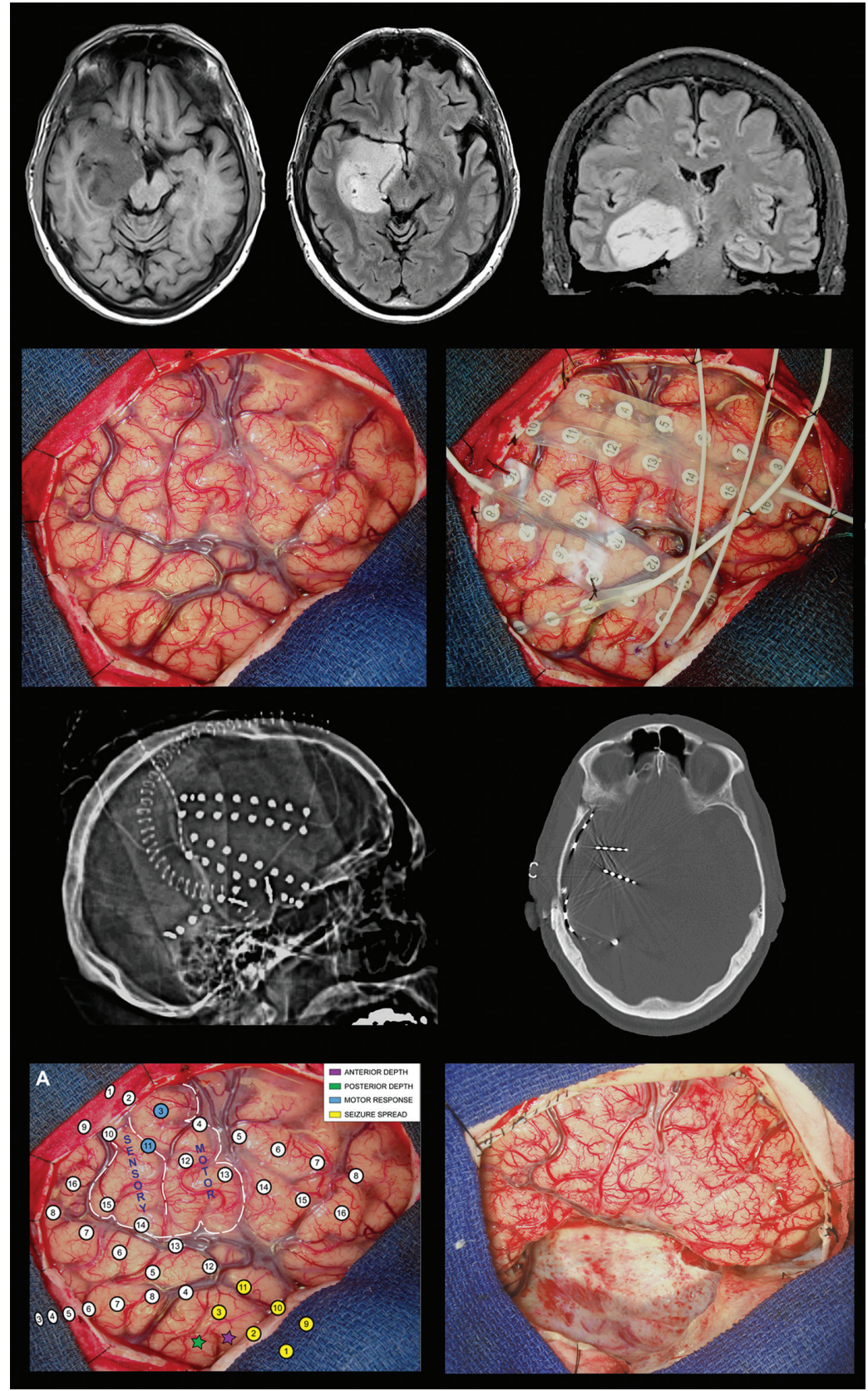

Figure 2. Surgical management of brain tumor-related epilepsy. This patient presented with recurrent seizures and a non-enhancing mass in the right medial temporal region (top row). Intraoperative photographs during intracranial electrode implantation (second row). Postsurgical CT scan showing placement of subdural grid electrodes and depth electrodes (third row). Intraoperative photographs showing intracranial electrode arrays with cortical mapping results and following resection of the tumor and epileptogenic tissue (bottom row). 
It is essential to identify patients where the tumor is not the primary epileptogenic focus, as they may benefit from a combined approach encompassing both tumor resection and epilepsy surgery (61).

Gross total resection can provide seizure freedom as high as up to $87 \%$ compared to 55\% seizure freedom with subtotal resection (63). Seizures in BTRE patients are best treated surgically irrespective of AEDs (40). It is also particularly important to note that surgery has its own risks. Proper discussion and informed consent with patient and family (if applicable) regarding risks, benefits, and alternatives to surgery is essential. Intractable epilepsy associated with brain tumors can significantly impact a patient's life. Studies suggest that early surgical resection is beneficial for disease control and improvement in quality of life $(4,56,63,64)$. Equivalent results were noted when compared to extent of surgical resection and seizure freedom $(58,63,65-67)$.

\section{CONCLUSION}

Among patients with brain tumors, seizures are one of the common presenting symptoms (10). Many studies have shown that tumors have intrinsic effects on surrounding normal brain tissue, causing it to become epileptogenic. As we discussed, pathogenesis of BTRE involves multiple factors such as tumor size, location, types of tumor, growth rate, peritumoral environmental changes, and much more which is still to be discovered. There is no evidence for AEDs as prophylaxis for brain tumor patients without seizures. However, in patients with BTRE, first- and second-generation AEDs are both beneficial medical treatment options. A carefully planned surgery can help patients with BTRE achieve complete seizure freedom and cytoreduction. With advances in EEG mapping technology and targeted therapies against tumors, a comprehensive multidisciplinary management approach should be undertaken and can help improve quality of life as well as long-term oncologic and seizure outcomes in patients suffering from brain tumor associated epilepsy.

Conflict of Interest: The authors declare no potential conflicts of interest with respect to research, authorship and/or publication of this article.

Copyright and Permission Statement: The authors confirm that the materials included in this chapter do not violate copyright laws. Where relevant, appropriate permissions have been obtained from the original copyright holder(s), and all original sources have been appropriately acknowledged or referenced.

\section{REFERENCES}

1. Moots PL, Maciunas RJ, Eisert DR, Parker RA, Laporte K, Abou-Khalil B. The course of seizure disorders in patients with malignant gliomas. Arch Neurol. 1995;52(7):717-24. https://doi.org/10.1001/ archneur.1995.00540310091021

2. Cohen N, Strauss G, Lew R, Silver D, Recht L. Should prophylactic anticonvulsants be administered to patients with newly-diagnosed cerebral metastases? A retrospective analysis. J Clin Oncol. 1988;6(10):1621-4. https://doi.org/10.1200/JCO.1988.6.10.1621 
3. Herman ST. Epilepsy after brain insult: targeting epileptogenesis. Neurology. 2002;59(9 Suppl 5): S21-6. https://doi.org/10.1212/WNL.59.9_suppl_5.S21

4. Glantz MJ, Cole BF, Forsyth PA, Recht LD, Wen PY, Chamberlain MC, et al. Practice parameter: anticonvulsant prophylaxis in patients with newly diagnosed brain tumors. Report of the Quality Standards Subcommittee of the American Academy of Neurology. Neurology. 2000;54(10):1886-93. https://doi.org/10.1212/WNL.54.10.1886

5. Olafsson E, Ludvigsson P, Gudmundsson G, Hesdorffer D, Kjartansson O, Hauser WA. Incidence of unprovoked seizures and epilepsy in Iceland and assessment of the epilepsy syndrome classification: a prospective study. Lancet Neurol. 2005;4(10):627-34. https://doi.org/10.1016/S1474-4422 (05)70172-1

6. Marcus LP, McCutcheon BA, Noorbakhsh A, Parina RP, Gonda DD, Chen C, et al. Incidence and predictors of 30-day readmission for patients discharged home after craniotomy for malignant supratentorial tumors in California (1995-2010). J Neurosurg. 2014;120(5):1201-11. https://doi. org/10.3171/2014.1.JNS131264

7. Chen DY, Chen CC, Crawford JR, Wang SG. Tumor-related epilepsy: epidemiology, pathogenesis and management. J Neurooncol. 2018;139(1):13-21. https://doi.org/10.1007/s11060-018-2862-0

8. Klinger NV, Shah AK, Mittal S. Management of brain tumor-related epilepsy. Neurol India. 2017;65(Supplement):S60-s70.

9. Lote K, Stenwig AE, Skullerud K, Hirschberg H. Prevalence and prognostic significance of epilepsy in patients with gliomas. Eur J Cancer. 1998;34(1):98-102. https://doi.org/10.1016/ S0959-8049(97)00374-2

10. Villemure JG, de Tribolet N. Epilepsy in patients with central nervous system tumors. Curr Opin Neurol. 1996;9(6):424-8. https://doi.org/10.1097/00019052-199612000-00005

11. Lynam LM, Lyons MK, Drazkowski JF, Sirven JI, Noe KH, Zimmerman RS, et al. Frequency of seizures in patients with newly diagnosed brain tumors: a retrospective review. Clin Neurol Neurosurg. 2007;109(7):634-8. https://doi.org/10.1016/j.clineuro.2007.05.017

12. Pace A, Bove L, Innocenti P, Pietrangeli A, Carapella CM, Oppido P, et al. Epilepsy and gliomas: incidence and treatment in 119 patients. J Exp Clin Cancer Res. 1998;17(4):479-82.

13. Oberndorfer S, Schmal T, Lahrmann H, Urbanits S, Lindner K, Grisold W. [The frequency of seizures in patients with primary brain tumors or cerebral metastases. An evaluation from the Ludwig Boltzmann Institute of Neuro-Oncology and the Department of Neurology, Kaiser Franz Josef Hospital, Vienna]. Wien Klin Wochenschr. 2002;114(21-22):911-6.

14. Goldlust SA, Hsu M, Lassman AB, Panageas KS, Avila EK. Seizure prophylaxis and melanoma brain metastases. J Neurooncol. 2012;108(1):109-14. https://doi.org/10.1007/s11060-012-0802-y

15. Sirven JI, Wingerchuk DM, Drazkowski JF, Lyons MK, Zimmerman RS. Seizure prophylaxis in patients with brain tumors: a meta-analysis. Mayo Clin Proc. 2004;79(12):1489-94. https://doi. org/10.4065/79.12.1489

16. Cascino GD. Epilepsy and brain tumors: implications for treatment. Epilepsia. 1990;31 Suppl 3: S37-44. https://doi.org/10.1111/j.1528-1157.1990.tb05858.x

17. Riva M. Brain tumoral epilepsy: a review. Neurol Sci. 2005;26 Suppl 1:S40-2. https://doi.org/10.1007/ s10072-005-0404-y

18. Wolf HK, Roos D, Blümcke I, Pietsch T, Wiestler OD. Perilesional neurochemical changes in focal epilepsies. Acta Neuropathol. 1996;91(4):376-84. https://doi.org/10.1007/s004010050439

19. Haacke EM, Mittal S, Wu Z, Neelavalli J, Cheng YC. Susceptibility-weighted imaging: technical aspects and clinical applications, part 1. AJNR Am J Neuroradiol. 2009;30(1):19-30. https://doi. org/10.3174/ajnr.A1400

20. Mittal S, Wu Z, Neelavalli J, Haacke EM. Susceptibility-weighted imaging: technical aspects and clinical applications, part 2. AJNR Am J Neuroradiol. 2009;30(2):232-52. https://doi.org/10.3174/ajnr.A1461

21. van Breemen MS, Wilms EB, Vecht CJ. Epilepsy in patients with brain tumours: epidemiology, mechanisms, and management. Lancet Neurol. 2007;6(5):421-30. https://doi.org/10.1016/ S1474-4422(07)70103-5

22. Buckingham SC, Robel S. Glutamate and tumor-associated epilepsy: glial cell dysfunction in the peritumoral environment. Neurochem Int. 2013;63(7):696-701. https://doi.org/10.1016/j. neuint.2013.01.027 
23. de Groot M, Iyer A, Zurolo E, Anink J, Heimans JJ, Boison D, et al. Overexpression of ADK in human astrocytic tumors and peritumoral tissue is related to tumor-associated epilepsy. Epilepsia. 2012;53(1):58-66. https://doi.org/10.1111/j.1528-1167.2011.03306.x

24. Boison D, Stewart KA. Therapeutic epilepsy research: from pharmacological rationale to focal adenosine augmentation. Biochem Pharmacol. 2009;78(12):1428-37. https://doi.org/10.1016/j.bcp. 2009.08.005

25. Seiffert E, Dreier JP, Ivens S, Bechmann I, Tomkins O, Heinemann U, et al. Lasting blood-brain barrier disruption induces epileptic focus in the rat somatosensory cortex. J Neurosci. 2004;24(36):7829-36. https://doi.org/10.1523/JNEUROSCI.1751-04.2004

26. Tewari BP, Chaunsali L, Campbell SL, Patel DC, Goode AE, Sontheimer H. Perineuronal nets decrease membrane capacitance of peritumoral fast spiking interneurons in a model of epilepsy. Nature communications. 2018;9(1):4724. https://doi.org/10.1038/s41467-018-07113-0

27. Nemani VM, Binder DK. Emerging role of gap junctions in epilepsy. Histol Histopathol. 2005; 20(1):253-9.

28. Aronica E, Gorter JA, Jansen GH, Leenstra S, Yankaya B, Troost D. Expression of connexin 43 and connexin 32 gap-junction proteins in epilepsy-associated brain tumors and in the perilesional epileptic cortex. Acta Neuropathol. 2001;101(5):449-59. https://doi.org/10.1007/s004010000305

29. Soroceanu L, Manning TJ Jr, Sontheimer H. Reduced expression of connexin-43 and functional gap junction coupling in human gliomas. Glia. 2001;33(2):107-17. https://doi.org/10.1002/1098-1136 (200102)33:2<107::AID-GLIA1010>3.0.CO;2-4

30. Jahromi SS, Wentlandt K, Piran S, Carlen PL. Anticonvulsant actions of gap junctional blockers in an in vitro seizure model. J Neurophysiol. 2002;88(4):1893-902. https://doi.org/10.1152/ jn.2002.88.4.1893

31. Juszczak GR, Swiergiel AH. Properties of gap junction blockers and their behavioural, cognitive and electrophysiological effects: animal and human studies. Prog Neuropsychopharmacol Biol Psychiatry. 2009;33(2):181-98. https://doi.org/10.1016/j.pnpbp.2008.12.014

32. Kalachikov S, Evgrafov O, Ross B, Winawer M, Barker-Cummings C, Martinelli Boneschi F, et al. Mutations in LGIl cause autosomal-dominant partial epilepsy with auditory features. Nat Genet. 2002;30(3):335-41. https://doi.org/10.1038/ng832

33. Morante-Redolat JM, Gorostidi-Pagola A, Piquer-Sirerol S, Sáenz A, Poza JJ, Galán J, et al. Mutations in the LGI1/Epitempin gene on 10q24 cause autosomal dominant lateral temporal epilepsy. Hum Mol Genet. 2002;11(9):1119-28. https://doi.org/10.1093/hmg/11.9.1119

34. Gu W, Brodtkorb E, Steinlein OK. LGIl is mutated in familial temporal lobe epilepsy characterized by aphasic seizures. Ann Neurol. 2002;52(3):364-7. https://doi.org/10.1002/ana.10280

35. Backman SA, Stambolic V, Suzuki A, Haight J, Elia A, Pretorius J, et al. Deletion of Pten in mouse brain causes seizures, ataxia and defects in soma size resembling Lhermitte-Duclos disease. Nat Genet. 2001;29(4):396-403. https://doi.org/10.1038/ng782

36. Beaumont A, Whittle IR. The pathogenesis of tumour associated epilepsy. Acta Neurochir (Wien). 2000;142(1):1-15. https://doi.org/10.1007/s007010050001

37. Shamji MF, Fric-Shamji EC, Benoit BG. Brain tumors and epilepsy: pathophysiology of peritumoral changes. Neurosurg Rev. 2009;32(3):275-86. https://doi.org/10.1007/s10143-009-0191-7

38. Hossmann KA, Seo K, Szymas J, Wechsler W. Quantitative analysis of experimental peritumoral edema in cats. Adv Neurol. 1990;52:449-58.

39. Wu Z, Mittal S, Kish K, Yu Y, Hu J, Haacke EM. Identification of calcification with MRI using susceptibility-weighted imaging: a case study. J Magn Reson Imaging. 2009;29(1):177-82. https://doi. org/10.1002/jmri.21617

40. Rudà R, Trevisan E, Soffietti R. Epilepsy and brain tumors. Curr Opin Oncol. 2010;22(6):611-20. https://doi.org/10.1097/CCO.0b013e32833de99d

41. Sheth RD. Adolescent issues in epilepsy. J Child Neurol. 2002;17 Suppl 2:2s23-2s7. https://doi.org/ 10.1177/08830738020170020801

42. Taphoorn MJ, Klein M. Cognitive deficits in adult patients with brain tumours. Lancet Neurol. 2004;3(3):159-68. https://doi.org/10.1016/S1474-4422(04)00680-5 
43. Zaatreh MM, Firlik KS, Spencer DD, Spencer SS. Temporal lobe tumoral epilepsy: characteristics and predictors of surgical outcome. Neurology. 2003;61(5):636-41. https://doi.org/10.1212/01. WNL.0000079374.78589.1B

44. Cavaliere R, Farace E, Schiff D. Clinical implications of status epilepticus in patients with neoplasms. Arch Neurol. 2006;63(12):1746-9. https://doi.org/10.1001/archneur.63.12.1746

45. DeLorenzo RJ, Pellock JM, Towne AR, Boggs JG. Epidemiology of status epilepticus. J Clin Neurophysiol. 1995;12(4):316-25. https://doi.org/10.1097/00004691-199512040-00003

46. Arik Y, Leijten FS, Seute T, Robe PA, Snijders TJ. Prognosis and therapy of tumor-related versus nontumor-related status epilepticus: a systematic review and meta-analysis. BMC Neurol. 2014;14:152. https://doi.org/10.1186/1471-2377-14-152

47. van Breemen MS, Rijsman RM, Taphoorn MJ, Walchenbach R, Zwinkels H, Vecht CJ. Efficacy of antiepileptic drugs in patients with gliomas and seizures. J Neurol. 2009;256(9):1519-26. https://doi. org/10.1007/s00415-009-5156-9

48. Fisher RS, Acevedo C, Arzimanoglou A, Bogacz A, Cross JH, Elger CE, et al. ILAE official report: a practical clinical definition of epilepsy. Epilepsia. 2014;55(4):475-82. https://doi.org/10.1111/epi.12550

49. Rosati A, Buttolo L, Stefini R, Todeschini A, Cenzato M, Padovani A. Efficacy and safety of levetiracetam in patients with glioma: a clinical prospective study. Arch Neurol. 2010;67(3):343-6. https://doi. org/10.1001/archneurol.2009.335

50. Rossetti AO, Jeckelmann S, Novy J, Roth P, Weller M, Stupp R. Levetiracetam and pregabalin for antiepileptic monotherapy in patients with primary brain tumors. A phase II randomized study. Neuro Oncol. 2014;16(4):584-8. https://doi.org/10.1093/neuonc/not170

51. Lee YJ, Kim T, Bae SH, Kim YH, Han JH, Yun CH, et al. Levetiracetam compared with valproic acid for the prevention of postoperative seizures after supratentorial tumor surgery: a retrospective chart review. CNS Drugs. 2013;27(9):753-9. https://doi.org/10.1007/s40263-013-0094-6

52. Maschio M. Brain tumor-related epilepsy. Curr Neuropharmacol. 2012;10(2):124-33. https://doi. org/10.2174/157015912800604470

53. Hildebrand J, Lecaille C, Perennes J, Delattre JY. Epileptic seizures during follow-up of patients treated for primary brain tumors. Neurology. 2005;65(2):212-5. https://doi.org/10.1212/01.wnl. $0000168903.09277 .8 \mathrm{f}$

54. Kwan P, Brodie MJ. Early identification of refractory epilepsy. N Engl J Med. 2000;342(5):314-9. https://doi.org/10.1056/NEJM200002033420503

55. Rheims S, Ducray F, Ryvlin P. Choosing the tumoral epilepsy surgery candidate. Epilepsia. 2013;54 Suppl 9:91-6. https://doi.org/10.1111/epi.12451

56. Luyken C, Blümcke I, Fimmers R, Urbach H, Elger CE, Wiestler OD, et al. The spectrum of longterm epilepsy-associated tumors: long-term seizure and tumor outcome and neurosurgical aspects. Epilepsia. 2003;44(6):822-30. https://doi.org/10.1046/j.1528-1157.2003.56102.x

57. Engel J Jr. Surgery for seizures. N Engl J Med. 1996;334(10):647-52. https://doi.org/10.1056/ NEJM199603073341008

58. Englot DJ, Berger MS, Barbaro NM, Chang EF. Predictors of seizure freedom after resection of supratentorial low-grade gliomas. A review. J Neurosurg. 2011;115(2):240-4. https://doi.org/ 10.3171/2011.3.JNS1153

59. Shah AK, Mittal S. Invasive electroencephalography monitoring: Indications and presurgical planning. Ann Indian Acad Neurol. 2014;17(Suppl 1):S89-94. https://doi.org/10.4103/0972-2327.128668

60. Jennum P, Dhuna A, Davies K, Fiol M, Maxwell R. Outcome of resective surgery for intractable partial epilepsy guided by subdural electrode arrays. Acta Neurol Scand. 1993;87(6):434-7. https://doi. org/10.1111/j.1600-0404.1993.tb04131.x

61. Mittal S, Barkmeier D, Hua J, Pai DS, Fuerst D, Basha M, et al. Intracranial EEG analysis in tumorrelated epilepsy: Evidence of distant epileptic abnormalities. Clin Neurophysiol. 2016;127(1): 238-44. https://doi.org/10.1016/j.clinph.2015.06.028

62. Awad IA, Rosenfeld J, Ahl J, Hahn JF, Lüders H. Intractable epilepsy and structural lesions of the brain: mapping, resection strategies, and seizure outcome. Epilepsia. 1991;32(2):179-86. https://doi. org/10.1111/j.1528-1157.1991.tb05242.x 
63. Englot DJ, Berger MS, Barbaro NM, Chang EF. Factors associated with seizure freedom in the surgical resection of glioneuronal tumors. Epilepsia. 2012;53(1):51-7. https://doi.org/10.1111/j.1528-1167. 2011.03269.x

64. Ramantani G, Kadish NE, Anastasopoulos C, Brandt A, Wagner K, Strobl K, et al. Epilepsy surgery for glioneuronal tumors in childhood: avoid loss of time. Neurosurgery. 2014;74(6):648-57. https://doi. org/10.1227/NEU.0000000000000327

65. Southwell DG, Garcia PA, Berger MS, Barbaro NM, Chang EF. Long-term seizure control outcomes after resection of gangliogliomas. Neurosurgery. 2012;70(6):1406-13; discussion 13-4. https://doi. org/10.1227/NEU.0b013e3182500a4c

66. Englot DJ, Han SJ, Berger MS, Barbaro NM, Chang EF. Extent of surgical resection predicts seizure freedom in low-grade temporal lobe brain tumors. Neurosurgery. 2012;70(4):921-8. https://doi. org/10.1227/NEU.0b013e31823c3a30

67. Bonney PA, Glenn CA, Ebeling PA, Conner AK, Boettcher LB, Cameron DM, et al. Seizure Freedom Rates and Prognostic Indicators After Resection of Gangliogliomas: A Review. World Neurosurg. 2015;84(6):1988-96. https://doi.org/10.1016/j.wneu.2015.06.044 